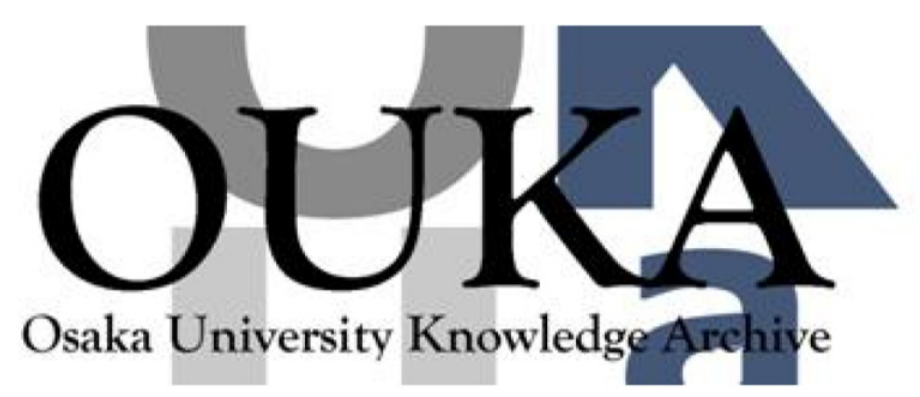

\begin{tabular}{|c|c|}
\hline Title & $\begin{array}{l}\text { Molecular dynamics simulation of silicon and } \\
\text { silicon dioxide etching by energetic halogen } \\
\text { beams }\end{array}$ \\
\hline Author (s) & Ohta, H.; Hamaguchi, S. \\
\hline Citation & $\begin{array}{l}\text { Journal of Vacuum Science and Technology, Part } \\
\text { A: Vacuum, Surfaces and Films. 19(5) p.2373- } \\
\text { p. } 2381\end{array}$ \\
\hline Issue Date & $2001-09$ \\
\hline oaire:version & VoR \\
\hline URL & https://hdl. handle. net/11094/78493 \\
\hline rights & $\begin{array}{l}\text { This article may be downloaded for personal use } \\
\text { on ly. Any other use requires prior permission } \\
\text { of the author and AIP Publishing. This article } \\
\text { appeared in Journal of Vacuum Science \& } \\
\text { Technology A 19, 2373 (2001) and may be found } \\
\text { at https://doi.org/10.1116/1.1385906. }\end{array}$ \\
\hline Note & \\
\hline
\end{tabular}

Osaka University Knowledge Archive : OUKA

https://ir. Library. osaka-u. ac. jp/

Osaka University 


\section{Molecular dynamics simulation of silicon and silicon dioxide etching by energetic halogen beams}

Cite as: Journal of Vacuum Science \& Technology A 19, 2373 (2001); https://doi.org/10.1116/1.1385906 Submitted: 20 December 2000 . Accepted: 21 May 2001. Published Online: 13 September 2001

\section{H. Ohta, and S. Hamaguchi}

\section{ARTICLES YOU MAY BE INTERESTED IN}

Overview of atomic layer etching in the semiconductor industry Journal of Vacuum Science \& Technology A 33, 020802 (2015); https:// doi.org/10.1116/1.4913379

\section{Classical interatomic potentials for $\mathrm{Si}-\mathrm{O}-\mathrm{F}$ and $\mathrm{Si}-\mathrm{O}-\mathrm{Cl}$ systems}

The Journal of Chemical Physics 115, 6679 (2001); https://doi.org/10.1063/1.1400789

Molecular dynamics simulations of Si etching by energetic $\mathrm{CF}_{3}^{+}$

Journal of Applied Physics 86, 5938 (1999); https://doi.org/10.1063/1.371637

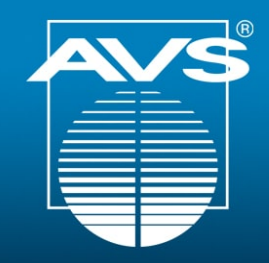

\section{Advance your science-and} career as a member of

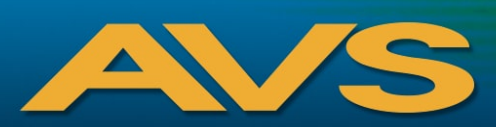

LEARN MORE 


\title{
Molecular dynamics simulation of silicon and silicon dioxide etching by energetic halogen beams
}

\author{
H. Ohta ${ }^{a)}$ and S. Hamaguchi ${ }^{\text {b) }}$ \\ Department of Fundamental Energy Science, Kyoto University, Gokasho, Uji, Kyoto 611-0011, Japan
}

(Received 20 December 2000; accepted 21 May 2001)

\begin{abstract}
Molecular dynamics simulations of silicon $(\mathrm{Si})$ and silicon dioxide $\left(\mathrm{SiO}_{2}\right)$ etching by energetic halogen (fluorine or chlorine) atoms in the energy range of 50-150 eV are performed using new sets of interatomic potentials for $\mathrm{Si}-\mathrm{O}-\mathrm{F}$ and $\mathrm{Si}-\mathrm{O}-\mathrm{Cl}$ systems. Etch rates and selectivities obtained from numerical simulations are compared with available experimental data. Etching mechanisms in the atomic scale, especially the difference between chlorine and fluorine direct ion etching characteristics, are discussed on the basis of the simulation results. (c) 2001 American Vacuum Society. [DOI: 10.1116/1.1385906]
\end{abstract}

\section{INTRODUCTION}

It is of great importance in semiconductor surface processing to understand plasma-surface interactions in the atomic scale and to create a database for fundamental surface reactions. Such understandings can facilitate further progress in process technologies for submicron structures with nanoscale accuracy. Unfortunately, due to the difficulty of precise in situ measurements of various surface reactions, our knowledge of fundamental reaction dynamics on the surface is currently limited. However, atomic-scale molecular dynamics (MD) simulations may be used to compensate for the lack of some experimental data and give insight into the mechanisms of fundamental surface reactions. One of the advantages of MD simulations is that one can perform controlled "experiments" under ideal conditions in order to elucidate particular aspects of reaction dynamics. Furthermore, a systematic parameter survey by MD simulations can be used to create a database for fundamental reactions cost effectively if the simulation data are critically checked against relevant experimental data.

One of the most essential and hardest tasks regarding classical MD simulations is the selection and/or construction of interatomic potentials representing the physical systems. The classical interatomic potentials for $\mathrm{Si}-\mathrm{F}$ and $\mathrm{Si}-\mathrm{Cl}$ systems were developed by Stillinger and Weber ${ }^{1-4}$ and by Feil et al. ${ }^{5}$ respectively. Using these potentials, several authors performed numerical simulations of silicon etching by $\mathrm{Cl}$ or $\mathrm{F}^{6-12}$ Improvement of these classical potentials for $\mathrm{Si}-\mathrm{F}$ and $\mathrm{Si}-\mathrm{Cl}$ systems were also attempted. Weakliem et al. and Carter et al. modified the original Stillinger-Weber (SW) potentials by fitting the potential functions to data obtained from the first-principle quantum mechanical calculations and, using the modified potentials, performed more realistic simulations for fluorine adsorption on Si surfaces. ${ }^{13-15}$ Hanson $e t$ al. also modified the $\mathrm{SW}$ potentials for $\mathrm{Si}-\mathrm{Cl}$ systems by adding embedded potential and four-body terms. Using the new potentials, they calculated $\mathrm{Si}$ etch rates by $\mathrm{Cl}$, showing the newly obtained etch rates are in better agreement

\footnotetext{
a)Electronic mail: ohta@center.iae.kyoto-u.ac.jp

${ }^{b)}$ Electronic mail: hamaguch@energy.kyoto-u.ac.jp
}

with experimental data than those obtained based on the original potentials. ${ }^{16,17}$

To the best of our knowledge, however, MD simulations of silicon dioxide $\left(\mathrm{SiO}_{2}\right)$ etching by halogen atoms had not been performed previously despite its importance as, e.g., hard masks for $\mathrm{Si}$ etching processes. This is probably because classical interatomic potentials for $\mathrm{Si}-\mathrm{O}-\mathrm{F}$ or $\mathrm{Si}-\mathrm{O}-\mathrm{Cl}$ systems were not previously available. Using previously available potentials, a few authors studied Ar sputtering of $\mathrm{SiO}_{2} \cdot{ }^{18-20} \mathrm{In}$ this article, we present MD simulation results for $\mathrm{SiO}_{2}$ etching by halogen atoms. For this purpose, we have constructed new sets of interatomic potentials for $\mathrm{Si}-\mathrm{O}-\mathrm{F}$ and $\mathrm{Si}-\mathrm{O}-\mathrm{Cl}$ systems based on data obtained from the first-principle quantum mechanical calculations and have completely rewritten our previous MD simulation $\operatorname{code}^{21}$ to incorporate multibody potentials.

The goal of this work is to understand details of silicon and silicon dioxide etching characteristics by energetic halogens. In this work, we focus on direct ion etching, where all reactive halogen atoms are directed to the surface with considerable energies. Therefore, MD simulations presented here correspond to ion beam etching, rather than reactive ion etching (RIE), where low-energy background neutral atoms covering the surface play important roles in surface reactions. Etch rates and selectivities (the ratios of silicon to oxide etch rates), which affect micron- or submicron-scale feature profiles, are obtained from numerical simulations. We also discuss etching mechanisms in the atomic scale based on MD simulation results, especially focusing on selectivities and different characteristics between chlorine and fluorine direct ion etching.

\section{MOLECULAR DYNAMICS SIMULATION}

To emulate the surface reactions just discussed by numerical simulations, we consider the following model. A single atom (either halogen or noble gas) is directed to the target with the normal incident angle. In the present work, the target is either $\mathrm{Si}$ or $\mathrm{SiO}_{2}$. In ion beam experiments, energetic ions impinging on the surface are expected to be neutralized right before interacting with the target surface due to an Auger emission process. Therefore, in our simula- 
TABLE I. Binding energies and bond lengths are shown.

\begin{tabular}{lccc}
\hline \hline & \multicolumn{2}{c}{ Binding energy } & \\
\cline { 2 - 3 } & $(\mathrm{eV})$ & $(\mathrm{kcal} / \mathrm{mol})$ & Bond length $(\AA)$ \\
\hline $\mathrm{Si}-\mathrm{Si}$ & 2.17 & 50.0 & 2.35 \\
$\mathrm{Si}-\mathrm{O}$ & 4.14 & 95.4 & 1.61 \\
$\mathrm{Si}-\mathrm{Cl}$ & 3.96 & 91.2 & 2.06 \\
$\mathrm{Cl}-\mathrm{Cl}$ & 2.47 & 56.9 & 1.96 \\
$\mathrm{Cl}-\mathrm{O}$ & 2.09 & 48.2 & 1.62 \\
$\mathrm{Si}-\mathrm{F}$ & 5.72 & 132 & 1.60 \\
$\mathrm{~F}-\mathrm{F}$ & 1.66 & 38.3 & 1.43 \\
$\mathrm{~F}-\mathrm{O}$ & 2.18 & 50.2 & 1.36 \\
\hline \hline
\end{tabular}

tions, only charge-neutral atoms are used as impinging species. It is also assumed that the target surface is kept charge neutral during the process. The energy range of impinging atoms employed in our numerical experiments is $50-150 \mathrm{eV}$ and the target surface is initially kept at $300 \mathrm{~K}$. For the sake of simplicity, polyatomic species are not used for impinging particles here.

To represent the aforementioned model numerically, we use classical molecular dynamics (MD) simulation. The interatomic potential functions are selected to reproduce binding energies, valences for covalent binding, and appropriate structures of the materials with good accuracy. As in earlier studies, ${ }^{5-10,12}$ we employ the SW potentials ${ }^{1-5}$ to represent interactions among $\mathrm{Si}$ and halogens (either $\mathrm{F}$ or $\mathrm{Cl}$ ). To model systems containing only $\mathrm{Si}$ and $\mathrm{O}$, we use the potential functions obtained by Watanabe et $a .^{22}$ In oxide etching simulations by halogens, however, we need to deal with ternary interactions among $\mathrm{Si}, \mathrm{O}$, and $\mathrm{F}$ (or $\mathrm{Cl}$ ). To the best of our knowledge, there had been no available classical potential functions to represent such interactions, so we have constructed SW type interatomic potentials for $\mathrm{Si}-\mathrm{O}-\mathrm{F}$ and $\mathrm{Si}-\mathrm{O}-\mathrm{Cl}$ systems, which are summarized in Appendix A. The potential functions were determined by nonlinearly fitting appropriate functional forms to potential energy data obtained from $a b$ initio quantum mechanical calculations. The obtained potential functions are compatible with the SW potentials for $\mathrm{Si}$ and halogen systems as well as the $\mathrm{Si}-\mathrm{O}$ system potentials of Watanabe et al. ${ }^{22}$ The derivation of the interatomic potentials for $\mathrm{Si}-\mathrm{O}-\mathrm{F}$ and $\mathrm{Si}-\mathrm{O}-\mathrm{Cl}$ systems will be published elsewhere. ${ }^{23}$ The interatomic potentials between $\mathrm{Ar}$ and other atoms are modeled by the repulsive Moliére pair potentials. ${ }^{24}$ Table I shows the energies and lengths of some representative bonds derived from the potential functions used in our simulations.

The equations of motion based on the interparticle potentials just mentioned are solved numerically with variable time steps determined from the velocity of the fastest particle. ${ }^{25}$ The typical time step in our simulation is $0.2-0.5$ fs which is small enough to guarantee good conservation of total energies of isolated systems. As shown in Fig. 1, the target material is placed in a simulation cell with periodic boundary conditions imposed in the horizontal directions. The atoms in the bottom layer are rigidly fixed to prevent the drift of the whole cell by the particle bombardment. The

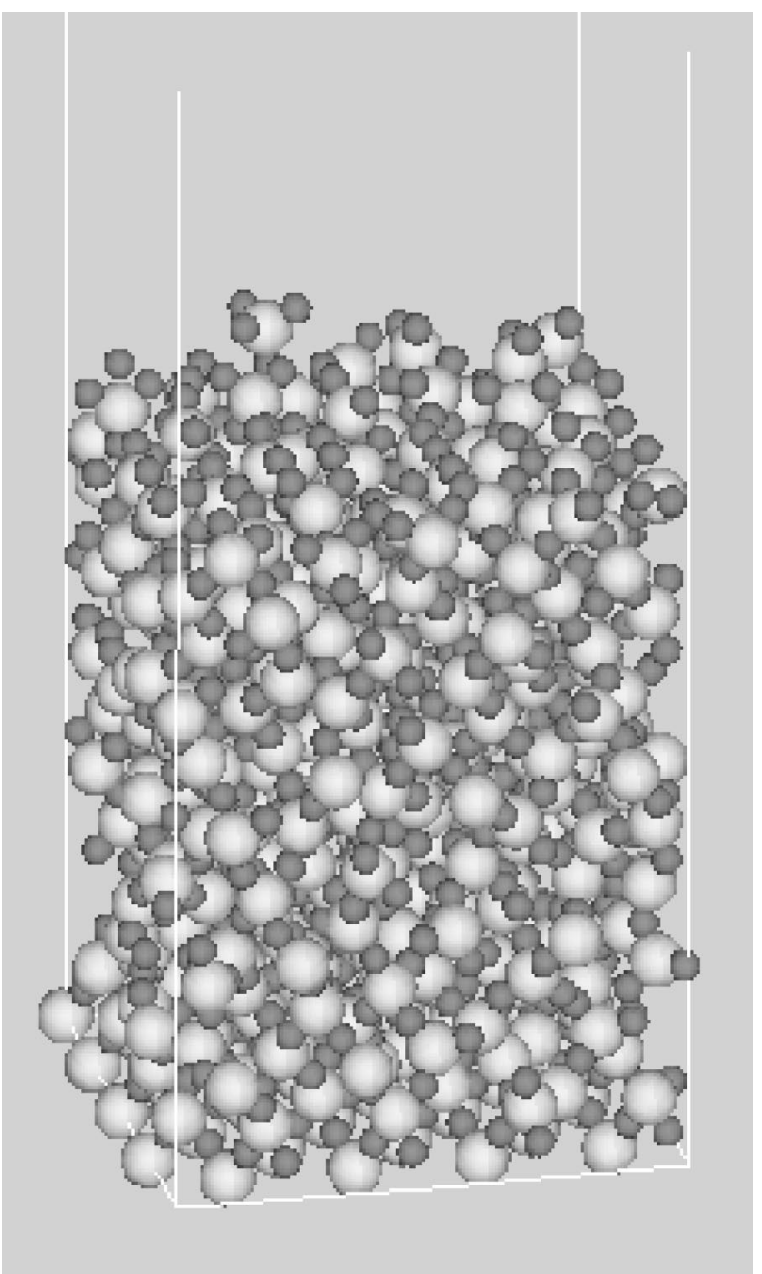

FIG. 1. The initial structure of a $\mathrm{SiO}_{2}$ target is shown. The simulation cell contains 384 silicon atoms (large white spheres) and 768 oxygen atoms (small gray spheres).

initial structures of the target are the diamond lattice for $\mathrm{Si}$ [with the top surface being (100)] and a relaxed amorphous structure initially arranged as the pseudo $\beta$ cristobalite for $\mathrm{SiO}_{2}$. Figure 1 shows an example of such amorphous structures of the oxide target. Physical quantities such as sputtering yields are measured only after surface conditions reach a "steady state" by sufficient particle bombardment. The simulation surface is a square of side length $21.7 \AA$ (the area is $472 \AA^{2}$ ) with a monolayer initially including $32 \mathrm{Si}$ atoms for the silicon target and $32 \mathrm{Si}$ and $64 \mathrm{O}$ atoms for the oxide target. We have also increased the simulation area up to 737 $\left(=27.2^{2}\right) \AA^{2}$ for some simulation runs and confirmed that the simulation surface size of $472\left(=21.7^{2}\right) \AA^{2}$ is sufficiently large to guarantee that obtained sputtering data are essentially independent of the area size under sputtering conditions employed in this work. Initially, the target materials are composed of 16 monolayers for $\mathrm{Si}$ (i.e., $512 \mathrm{Si}$ atoms) and 12 monolayers for oxide (i.e., $384 \mathrm{Si}$ atoms and $768 \mathrm{O}$ atoms, totaling 1152 atoms), the depths of which are $21 \AA$ for $\mathrm{Si}$ and $32 \AA$ for oxide. Energetic particles are injected from randomly chosen locations just above the target in the direction normal to the surface. It is sometimes more convenient 
to measure the dose of impinging particles in units of monolayer (ML), with $1 \mathrm{ML}$ corresponding to 32 impinging particles in both $\mathrm{Si}$ and oxide cases in our simulation. The bombardment process by a single energetic particle is then repeated about 1000 times (i.e., about $31 \mathrm{ML}$ ) to increase statistics for the measurement of macroscopic parameters such as sputtering yields.

Most transient etching processes such as breaking and reformation of bonds by particle bombardment typically occur within a picosecond. On the other hand, under ordinary plasma processing conditions, the interval between two successive ion injection into such a small simulation surface area is of order $1 \mu \mathrm{s}$. Therefore, each ion bombardment may be considered as an independent process. To simulate such independent processes efficiently, for the first $0.7 \mathrm{ps}$ after an energetic particle hits the surface, the motion of all particles are solved numerically except for those on the rigidly fixed bottom layer. Then, we apply artificial cooling to all the particles for $0.3 \mathrm{ps}$, using Berendsen's heat removal scheme ${ }^{26}$ with a coupling constant of $2.0 \times 10^{-14} \mathrm{~s}^{-1}$. At the end of the cooling process, a new energetic particle is directed again to the surface and the whole simulation cycle is repeated. Etching products-defined as (clusters of) atoms that are isolated from the surface and have momentum in the direction away from surface-are automatically detected and recorded during simulations and then removed from the simulation cell at the end of each simulation cycle. To avoid depletion of simulation particles, a new layer of atoms is automatically added to the simulation cell from the bottom occasionally.

The surface conditions greatly influence sputtering yields. One of the critical issues pertaining to such MD simulations is how to obtain the "typical" surface in an etching process. As we have mentioned earlier, we start from a clean target surface and continue to bombard the surface until we observe the surface roughness and properties of the halogenated layer (in the case of halogen bombardment) reach a steady state. We measure physical quantities such as etch rates only after surface conditions reach such a steady state, which is typically after bombardment of about $10 \mathrm{ML}$ atoms.

The question then arises whether the surface conditions in such steady states actually represent the typical surface conditions. It is not easy to answer this question since we artificially cool the surface $0.7 \mathrm{ps}$ after each ion impingement, which quenches the surface morphology quite rapidly. Such artificial cooling processes are necessary in MD simulations to prevent the simulation system from being unrealistically heated up. In a real system, however, the energy deposited in a small region near the surface dissipates by phonon propagation and thermal diffusion. These dissipation processes take place in a much longer time scale than the artificial cooling process, which lasts only for $0.3 \mathrm{ps}$ in our simulation. Of course, it is not practical to simulate such long-time dissipation processes directly by MD simulations. Therefore steady-state surfaces obtained in our MD simulations may be somewhat rougher than the actual surfaces during etching processes.
In etching simulations, we sometimes observe large clusters of atoms (i.e., molecules or radicals) are desorbed from the surface. Although such events are not so frequent, even a small number of such clusters can significantly increase sputtering yields since the number of atoms constituting such clusters can be very large. Desorption of large molecules and clusters may indeed occur in actual etching processes. However, we think it is much less frequent than we observe in our numerical simulations since, as we have noted, surfaces obtained in MD simulations may be rougher than the actual surfaces, i.e., surface atoms in MD simulations may be less firmly bonded. In what follows, therefore, we define the sputtering yield $Y$ of $\mathrm{Si}$ from the $\mathrm{Si}$ or $\mathrm{SiO}_{2}$ surface as the number of $\mathrm{Si}$ atoms desorbed in the form of $\mathrm{SiCl}_{x}$ or $\mathrm{SiCl}_{x} \mathrm{O}_{y}$ ( $x$ and $y \geqslant 0$ ) par $\mathrm{Cl}$ impact $\left(\mathrm{SiF}_{x}\right.$ or $\mathrm{SiF}_{x} \mathrm{O}_{y}$ par $\mathrm{F}$ impact). In other words, we ignore desorbed clusters containing more than two $\mathrm{Si}$ atoms in evaluating the sputtering yield. In this sense, yield $Y$ defined here gives a lower bound of the actual sputtering yield. However, as we have observed in our simulations and as also demonstrated in earlier Si etching simulations by Hanson et al. ${ }^{16,17}$ desorbed products are predominantly clusters containing single $\mathrm{Si}$ atoms. Therefore, sputtering yield $Y$ thus defined is expected to be sufficiently close to the actual sputtering yield.

\section{RESULTS AND DISCUSSION}

\section{A. Si etching}

Molecular dynamics simulations for halogen/silicon etching have been performed extensively by many authors ${ }^{5-10,12,16,17}$ using various potential forms and different surface conditions. In order to evaluate $\mathrm{Si}$ and $\mathrm{SiO}_{2}$ etch rates on the same footing so that we can obtain the selectivity self-consistently, we have also performed MD simulations for Si etching with the SW potentials. Table II lists Si sputtering yields for silicon and oxide targets obtained from our MD simulations. Sputtering yield $Y$ is defined in the preceding section. For comparison, we also list yield $Y_{2}$, which is defined as the number of $\mathrm{Si}$ atoms desorbed in the form of clusters containing up to $2 \mathrm{Si}$ atoms (e.g., clusters such as $\mathrm{Si}_{m} \mathrm{Cl}_{x}$ or $\mathrm{Si}_{m} \mathrm{Cl}_{x} \mathrm{O}_{y}$ with $m=1$ and 2 for $\mathrm{Cl}$ impact) par impact atom. Clearly, $Y \leqslant Y_{2}$. As we discussed previously, however, $Y_{2}$ may overestimate the actual sputtering yield. The sputtering yields due to pure physical sputtering, i.e., sputtering by Ar atoms, are also listed in Table II. Large sputtering yields for halogens are generally attributed to chemical effects, as we shall discuss momentarily.

The sputtering yields presented in this work are obtained by averaging the yield values from the 321st to 960th impact (11-30 ML runs). The surface may be considered to have reached the steady state if (a) the depth of halogenated layer, (b) fractions of each element in the halogenated layer, and (c) the number of halogens (i.e., halogen content) in the simulation cell are all observed to become almost constant. This typically occurs after $10 \mathrm{ML}$ atomic bombardment in our MD simulations, as mentioned before. The values of (a)-(c) mentioned in steady states averaged over 11-30 ML simulation cycles are given in Table III. Here, the depth of a 
TABLE II. Silicon sputtering yields obtained from MD simulations under various etching conditions are shown. Sputtering yield $Y$ denotes the number of $\mathrm{Si}$ atoms desorbed from the surface in the form of $\mathrm{SiC}_{x}$ or $\mathrm{SiC}_{x} \mathrm{O}_{y}\left(\mathrm{SiF}_{x}\right.$ or $\mathrm{SiF}_{x} \mathrm{O}_{y}$ ) per impact atom. For the definition of $Y_{2}$, see the main text. The yields are averages over 321-960 (11-30 ML) impact runs.

\begin{tabular}{lll}
\hline \hline Target/Beam & \multicolumn{1}{c}{$Y$} & \multicolumn{1}{c}{$Y_{2}$} \\
\hline $\mathrm{Si} / \mathrm{Cl} 20 \mathrm{eV}$ & 0.10 & 0.13 \\
$\mathrm{Si} / \mathrm{Cl} 30 \mathrm{eV}$ & 0.16 & 0.19 \\
$\mathrm{Si} / \mathrm{Cl} 50 \mathrm{eV}$ & 0.26 & 0.31 \\
$\mathrm{Si} / \mathrm{Cl} 100 \mathrm{eV}$ & 0.46 & 0.57 \\
$\mathrm{Si} / \mathrm{Cl} 150 \mathrm{eV}$ & 0.67 & 0.84 \\
$\mathrm{Si} / \mathrm{F} 50 \mathrm{eV}$ & 0.42 & 0.47 \\
$\mathrm{Si} / \mathrm{F} 100 \mathrm{eV}$ & 0.51 & 0.60 \\
$\mathrm{Si} / \mathrm{F} 150 \mathrm{eV}$ & 0.62 & 0.75 \\
$\mathrm{Si} / \mathrm{Ar} 50 \mathrm{eV}$ & 0.011 & 0.011 \\
$\mathrm{Si} / \mathrm{Ar} 100 \mathrm{eV}$ & 0.084 & 0.088 \\
$\mathrm{Si} / \mathrm{Ar} 150 \mathrm{eV}$ & 0.15 & 0.16 \\
$\mathrm{SiO} / \mathrm{Cl} 50 \mathrm{eV}$ & 0.020 & 0.023 \\
$\mathrm{SiO} / \mathrm{Cl} 100 \mathrm{eV}$ & 0.11 & 0.13 \\
$\mathrm{SiO}_{2} / \mathrm{Cl} 150 \mathrm{eV}$ & 0.15 & 0.21 \\
$\mathrm{SiO}_{2} / \mathrm{F} 50 \mathrm{eV}$ & 0.12 & 0.16 \\
$\mathrm{SiO}_{2} / \mathrm{F} 100 \mathrm{eV}$ & 0.20 & 0.25 \\
$\mathrm{SiO}_{2} / \mathrm{F} 150 \mathrm{eV}$ & 0.22 & 0.30 \\
$\mathrm{SiO}_{2} / \mathrm{Ar} 50 \mathrm{eV}$ & 0.0031 & 0.0031 \\
$\mathrm{SiO}_{2} / \mathrm{Ar} 100 \mathrm{eV}$ & 0.039 & 0.045 \\
$\mathrm{SiO}_{2} / \mathrm{Ar} 150 \mathrm{eV}$ & 0.067 & 0.092 \\
\hline \hline
\end{tabular}

halogenated layer is defined, for the sake of simplicity, as the distance between the most deeply penetrated halogen atom and the atom of any kind located in the highest position of the target.

Figure 2 plots the sputtering yields ( $Y$ in Table II) for $\mathrm{Si}$ targets. Here $\bigcirc, \square$, and $\triangle$ indicate the Si sputtering yields by $\mathrm{Cl}, \mathrm{F}$, and $\mathrm{Ar}$ impact, respectively. We note that these values are in good agreement with earlier simulation results given in Refs. 7, 9, 16, and 17. The fitting curves shown in Fig. 2 are based on the function (Ref. 27) $Y=A\left(E^{1 / 2}-B\right)$, where $E$ is the incident energy in $\mathrm{eV}$ and the obtained fitting

TABLE III. Halogenated layer depths, fractions of elements in the halogenated layers, and halogen contents in the simulation cell obtained from MD simulations. The values are averages over 321-960 (11-30 ML) impact runs.

\begin{tabular}{lccccc}
\hline \hline & & \multicolumn{5}{c}{ Fraction of Elements } \\
\cline { 3 - 5 } Target/Beam & Depth $(\AA)$ & $\mathrm{Si}$ & $\mathrm{Cl}$ or F & $\mathrm{O}$ & \multicolumn{1}{c}{ Cl or F content } \\
\hline $\mathrm{Si} / \mathrm{Cl} 20 \mathrm{eV}$ & 13 & 0.65 & 0.35 & $\cdots$ & $53(1.7 \mathrm{ML})$ \\
$\mathrm{Si} / \mathrm{Cl} 30 \mathrm{eV}$ & 15 & 0.67 & 0.33 & $\cdots$ & $56(1.7 \mathrm{ML})$ \\
$\mathrm{Si} / \mathrm{Cl} 50 \mathrm{eV}$ & 23 & 0.82 & 0.18 & $\cdots$ & $62(1.9 \mathrm{ML})$ \\
$\mathrm{Si} / \mathrm{Cl} 100 \mathrm{eV}$ & 27 & 0.83 & 0.17 & $\cdots$ & $60(1.9 \mathrm{ML})$ \\
$\mathrm{Si} / \mathrm{Cl} 150 \mathrm{eV}$ & 32 & 0.84 & 0.16 & $\cdots$ & $68(2.1 \mathrm{ML})$ \\
$\mathrm{Si} / \mathrm{F} 50 \mathrm{eV}$ & 31 & 0.75 & 0.25 & $\cdots$ & $107(3.4 \mathrm{ML})$ \\
$\mathrm{Si} / \mathrm{F} 100 \mathrm{eV}$ & 43 & 0.74 & 0.26 & $\cdots$ & $155(4.8 \mathrm{ML})$ \\
$\mathrm{Si} / \mathrm{F} 150 \mathrm{eV}$ & 49 & 0.80 & 0.20 & $\cdots$ & $141(4.4 \mathrm{ML})$ \\
$\mathrm{SiO}_{2} / \mathrm{Cl} 50 \mathrm{eV}$ & 13 & 0.27 & 0.23 & 0.50 & $59(1.8 \mathrm{ML})$ \\
$\mathrm{SiO}_{2} / \mathrm{Cl} 100 \mathrm{eV}$ & 28 & 0.29 & 0.16 & 0.55 & $92(2.9 \mathrm{ML})$ \\
$\mathrm{SiO}_{2} / \mathrm{Cl} 150 \mathrm{eV}$ & 27 & 0.30 & 0.15 & 0.55 & $69(2.2 \mathrm{ML})$ \\
$\mathrm{SiO}_{2} / \mathrm{F} 50 \mathrm{eV}$ & 23 & 0.26 & 0.22 & 0.52 & $114(3.6 \mathrm{ML})$ \\
$\mathrm{SiO}_{2} / \mathrm{F} 100 \mathrm{eV}$ & 29 & 0.28 & 0.20 & 0.52 & $107(3.3 \mathrm{ML})$ \\
$\mathrm{SiO}_{2} / \mathrm{F} 150 \mathrm{eV}$ & 38 & 0.30 & 0.18 & 0.53 & $125(3.9 \mathrm{ML})$ \\
\hline \hline
\end{tabular}

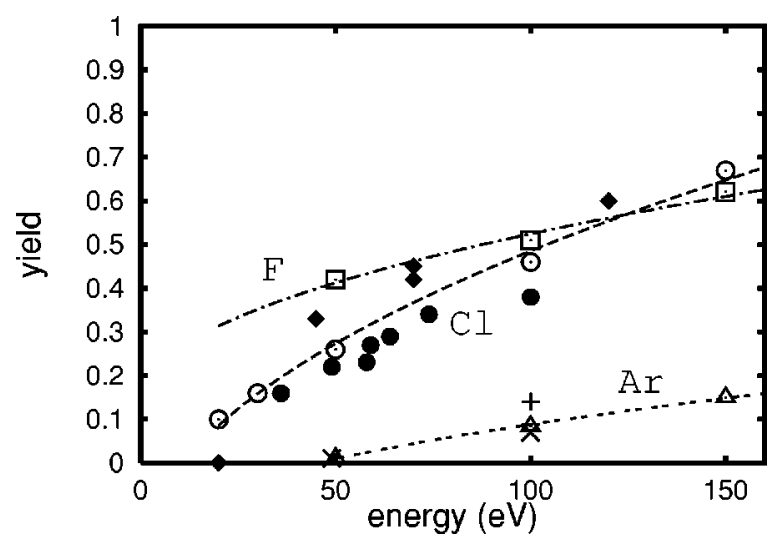

FIG. 2. Silicon sputtering yields (given by $Y$ in Table II) of the silicon target for $\mathrm{Cl}(\bigcirc), \mathrm{F}(\square)$, and $\operatorname{Ar}(\triangle)$ beam etching are shown. Experimental data for $\mathrm{Cl}^{+}$beam etching by Chang and Sawin (Ref. 28) and chlorine plasma etching by Holber et al. (Ref. 29) are denoted by 's and 's respectively. Experimental data for Si sputtering by Ar beams are denoted by $\times$ 's [obtained by Chang et al. (Ref. 30)] and +'s [obtained by Tachi and Okudaira (Ref. 31)]. The dashed, dotted-dashed, and dotted curves are yield fitting curves for $\mathrm{Cl}, \mathrm{F}$, and $\mathrm{Ar}$ beam etching processes, respectively, as given in the main text.

parameters are $A=0.0382$ and $B=-3.73$ for $\mathrm{F}, A=0.0723$ and $B=3.29$ for $\mathrm{Cl}$, and $A=0.0268$ and $B=6.72$ for Ar. If $B \geqslant 0$, the threshold energy is given by $E_{\mathrm{th}}=B^{2}$ and we have obtained $E_{\mathrm{th}} \simeq 11 \mathrm{eV}$ for $\mathrm{Cl}$ and $E_{\mathrm{th}} \simeq 45 \mathrm{eV}$ for Ar.

For comparison, experimentally obtained $\mathrm{Si}$ yields are also plotted in Fig. 2: ''s denote data from $\mathrm{Cl}^{+}$beam etching by Chang and Sawin ${ }^{28}$ and 's from chlorine plasma etching by Holber and Forster. ${ }^{29}$ Experimental data of $\mathrm{Si}$ yields by Ar beam etching are denoted by $\times$ 's (obtained by Chang et al. $)^{30}$ and +'s (obtained by Tachi and Okudaira.) $)^{31}$ Our simulation results are shown to be in good agreement with the experimental data. The simulation results show that sputtering yields by $\mathrm{F}$ impact are larger than those by $\mathrm{Cl}$ impact in the energy range less than around $120 \mathrm{eV}$ and are smaller in the higher-energy range. This is consistent with experimental observations by Tachi and Okudaira. ${ }^{31}$ Such a crossover of sputtering yields may be explained in the following manner.

As the $\mathrm{Si}-\mathrm{F}$ and $\mathrm{Si}-\mathrm{Cl}$ bond lengths given in Table I indicate, the size of a fluorine atom is much smaller than that of a chlorine atom. Therefore, with the same impact energy, fluorine atoms can penetrate the $\mathrm{Si}$ target more deeply than chlorine atoms. In addition, the $\mathrm{Si}-\mathrm{F}$ binding energy is higher than the $\mathrm{Si}-\mathrm{Cl}$ binding energy, so $\mathrm{F}$ atoms are more easily bound by $\mathrm{Si}$ atoms once they are in the $\mathrm{Si}$ target. This is consistent with the $a b$ initio calculation results by Seel and Bagus, ${ }^{32}$ which have shown that the penetration energy barrier into $\mathrm{Si}$ clusters is significantly higher for $\mathrm{Cl}$ than that for F. These effects result in deeper halogenated layers and higher halogen concentrations in the layers for sputtering by $\mathrm{F}$ atoms, as shown in Table III. Note that, in halogenated layers, many $\mathrm{Si}$ bonds are terminated by halogen atoms in such a way that $\mathrm{Si}$ atoms are more weakly bound with other $\mathrm{Si}$ atoms and therefore more likely to be removed by atomic impact than those in the original Si crystal. Sputtering en- 


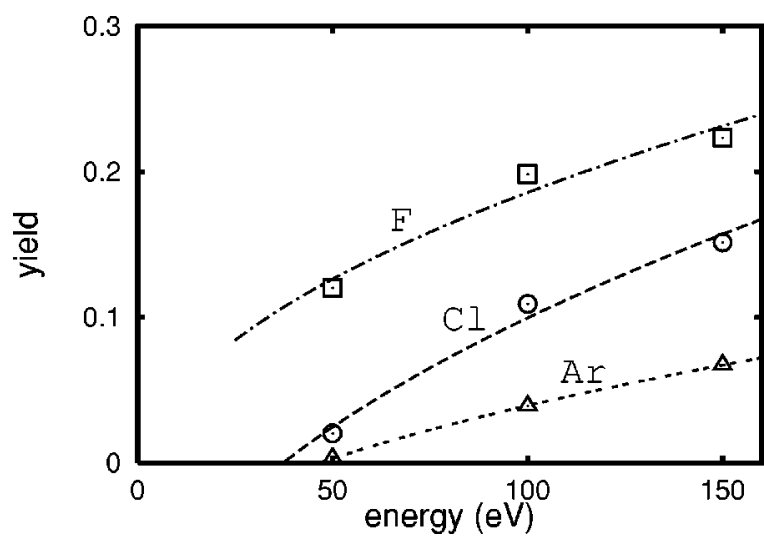

FIG. 3. Silicon sputtering yields (given by $Y$ in Table II) of the oxide $\left(\mathrm{SiO}_{2}\right)$ target for $\mathrm{Cl}(\bigcirc), \mathrm{F}(\square)$, and $\operatorname{Ar}(\triangle)$ beam etching are shown. The dashed, dotted-dashed, and dotted curves are yield fitting curves for $\mathrm{Cl}, \mathrm{F}$, and $\mathrm{Ar}$ beam etching processes, respectively, as given in the main text.

hanced by chemical reactions are called chemical sputtering. In the low-energy regime, impinging $\mathrm{F}$ atoms have higher sputtering yields than $\mathrm{Cl}$ atoms since $\mathrm{F}$ atoms can form more effective halogenated layers.

In the higher energy regime, both $\mathrm{Cl}$ and $\mathrm{F}$ atoms can halogenate the target surface sufficiently. However, as shown in Table III, the depth of the fluorinated layer is much larger than the chlorinated layer for the same impact energy. In other words, with the same impact energy, an impinging $\mathrm{F}$ atom travels longer in the deep fluorinated layer before releasing its kinetic energy completely whereas an impinging $\mathrm{Cl}$ atom releases most of its kinetic energy in the shallow chlorinated layer. Therefore, the incoming kinetic energy is more efficiently used to break surface bonds in the case of $\mathrm{Cl}$ sputtering, which results in higher sputtering yields for $\mathrm{Cl}$ in the high-energy regime.

\section{B. $\mathrm{SiO}_{2}$ etching}

The sputtering yields ( $Y$ in Table II) for oxide targets are plotted in Fig. 3. Here $\bigcirc, \square$, and $\triangle$ denote Si sputtering yields by $\mathrm{Cl}, \mathrm{F}$, and Ar impact, respectively. As in Fig. 2, the functional form $Y=A\left(E^{1 / 2}-B\right)$ was used to fit the yield data, where the fitting parameters are $A=0.0203$ and $B$ $=0.850$ for $\mathrm{F}, A=0.0256$ and $B=6.11$ for $\mathrm{Cl}$, and $A$ $=0.0124$ and $B=6.83$ for Ar. The estimated threshold energy is $E_{\mathrm{th}}\left(=B^{2}\right) \simeq 37 \mathrm{eV}$ for $\mathrm{Cl}$ and $E_{\mathrm{th}} \simeq 47 \mathrm{eV}$ for Ar.

The Si sputtering yields of oxide by Ar impact obtained from our simulations agree with earlier MD simulation results based on different interatomic potentials. ${ }^{18}$ Our estimate of the oxide etching threshold energy $E_{\text {th }} \simeq 47 \mathrm{eV}$ is in good agreement with that by Holber and Forster. ${ }^{29}$ Oostra et al. have also confirmed experimentally that oxide etching does not occur for $\mathrm{Ar}^{+}$impact with normal incidence at about 50 $\mathrm{eV} .{ }^{33}$ Note that sputtering yields by $\mathrm{Ar}$ beams for $\mathrm{SiO}_{2}$ is much smaller than that for $\mathrm{Si}$ since the $\mathrm{Si}-\mathrm{O}$ binding energy is significantly higher than the $\mathrm{Si}-\mathrm{Si}$ binding energy.

Since in the bulk of $\mathrm{SiO}_{2}$ each silicon atom has four $\mathrm{Si}-\mathrm{O}$ covalent bonds whereas each oxygen atom has only two, oxygen atoms can be more easily removed by physical sputtering than silicon atoms. In the early stage of simulation where a clean $\mathrm{SiO}_{2}$ target surface is subject to the atomic bombardment, we observe that more oxygen atoms are removed from the surface than $\mathrm{Si}$ atoms. A similar phenomenon was observed in earlier MD simulations for Ar sputtering of oxide targets. ${ }^{19,20}$ In the case of halogen sputtering, the remaining excessive silicon atoms on the surface are then removed efficiently by the combination of physical and chemical sputtering, as in the case of silicon etching by halogens. In steady states, physical sputtering of oxygen atoms and physical/chemical sputtering of $\mathrm{Si}$ atoms are balanced.

The fact that oxygen atoms are more easily removed from

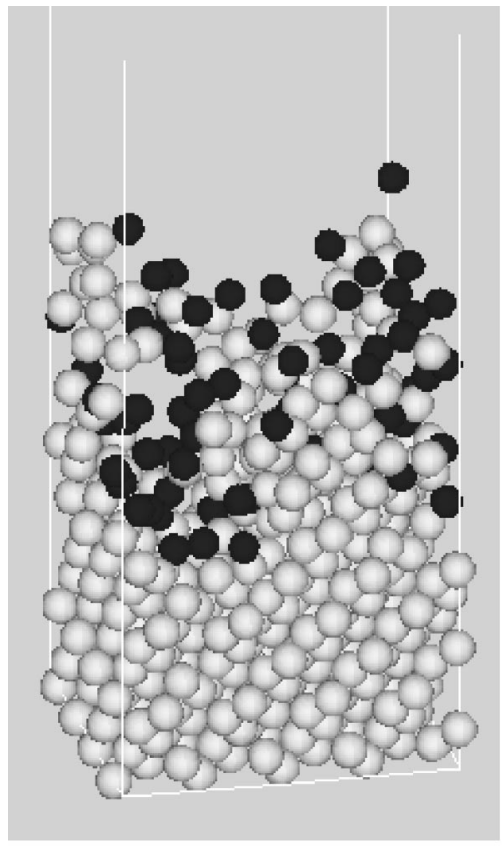

(a)

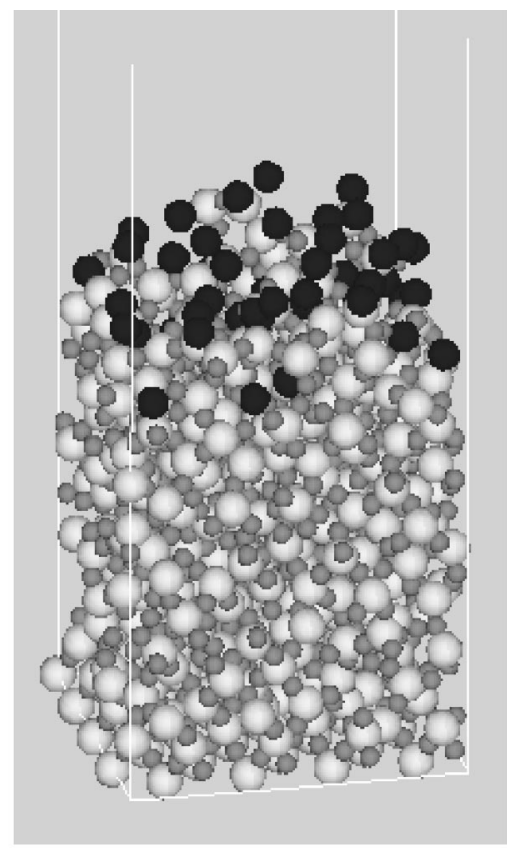

(b)
FIG. 4. Typical surface structures during $50 \mathrm{eV} \mathrm{Cl}$ beam etching; the $\mathrm{Si} \mathrm{(a)} \mathrm{and} \mathrm{SiO}_{2}$ (b) targets are shown. Large white spheres are $\mathrm{Si}$ atoms, small gray spheres are $\mathrm{O}$ atoms, and large black spheres are $\mathrm{Cl}$ atoms. 


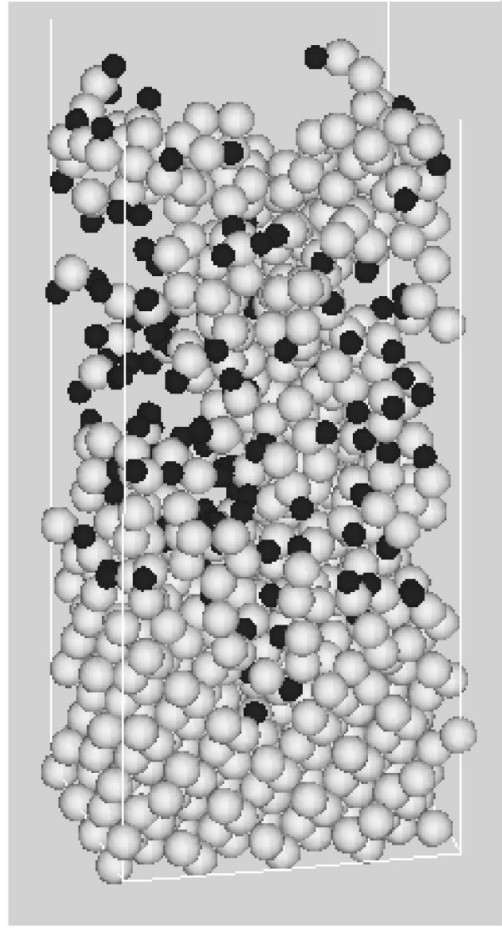

(a)

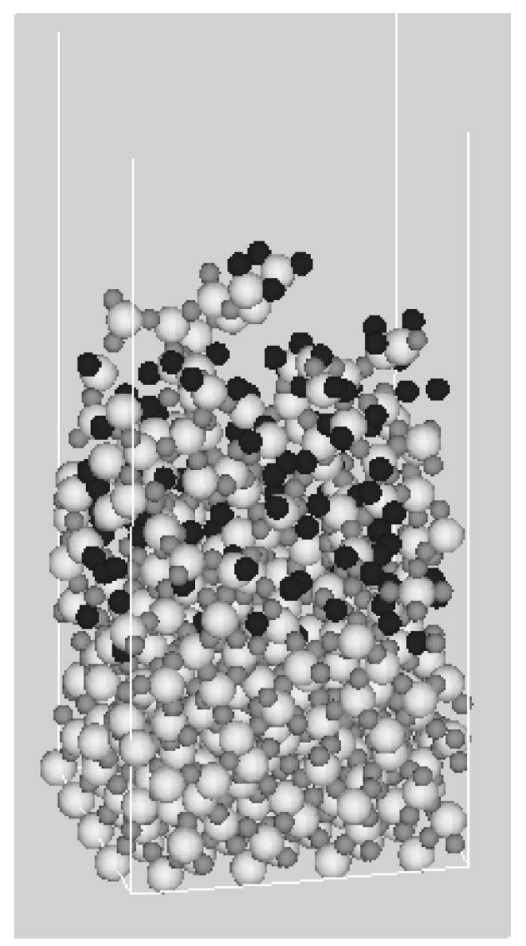

(b)

FIG. 5. Typical surface structures during $100 \mathrm{eV} \mathrm{F}$ beam etching; the $\mathrm{Si}$ (a) and $\mathrm{SiO}_{2}$ (b) targets are shown. Large white spheres are $\mathrm{Si}$ atoms, small gray spheres are $\mathrm{O}$ atoms, and small black spheres are $\mathrm{F}$ atoms.

the oxide surface during Ar impact accounts for our observation that the sputtering threshold energies for $\mathrm{Si}$ and $\mathrm{SiO}_{2}$ targets are almost the same (i.e., $45-47 \mathrm{eV}$ ). The threshold energy of Si sputtering from an oxide target is essentially determined by that from the pure $\mathrm{Si}$ surface since the $\mathrm{Si}$ concentration is significantly higher on the oxide surface than that in the bulk under Ar bombardment.

It is shown in Fig. 3 that the threshold energy of oxide etching by $\mathrm{Cl}$ impact is close to that by Ar sputtering. This is because oxide etching by $\mathrm{Cl}$ is almost pure physical sputtering in this energy regime. Figure 4 shows typical surface structures during $50 \mathrm{eV} \mathrm{Cl}$ beam etching. Figures 4(a) and 4(b) show $\mathrm{Si}$ and $\mathrm{SiO}_{2}$ targets. It is seen that, at $50 \mathrm{eV}$ impact energy, most of the $\mathrm{Cl}$ atoms stay on the top of the oxide target whereas a significant number of $\mathrm{Cl}$ atoms penetrate a few monolayers of the Si target. The difficulty for $\mathrm{Cl}$ atoms to penetrate the oxide may be caused by the facts (1) that the $\mathrm{Si}-\mathrm{O}$ bond length is much smaller than the $\mathrm{Si}-\mathrm{Si}$ bond length so that there is less room for $\mathrm{Cl}$ atoms to go through in the oxide target and (2) that the $\mathrm{Si}-\mathrm{O}$ binding energy is much higher than the $\mathrm{Si}-\mathrm{Si}$ binding energy. Therefore, at around $50 \mathrm{eV}$, impinging $\mathrm{Cl}$ atoms have only minor contributions to weakening $\mathrm{Si}-\mathrm{O}$ bonds near the surface, resulting in little chemical enhancement for sputtering yields. As the $\mathrm{Cl}$ impact energy increases, however, $\mathrm{Cl}$ atoms penetrate the target more deeply and chemical enhancement of sputtering yields increases. For Si etching, however, the chemical enhancement of sputtering yields by $\mathrm{Cl}$ is much more significant than for $\mathrm{SiO}_{2}$ etching and thus sputtering yields of $\mathrm{Si}$ are higher. This is because the $\mathrm{Si}-\mathrm{Cl}$ binding energy is almost twice as large as the $\mathrm{Si}-\mathrm{Si}$ binding energy, so that $\mathrm{Cl}$ atoms terminating $\mathrm{Si}$ bonds are stable in Si targets. On the other hand, the $\mathrm{Si}-\mathrm{Cl}$ binding energy is slightly lower and the $\mathrm{Cl}-\mathrm{O}$ binding energy is much lower than the $\mathrm{Si}-\mathrm{O}$ binding energy, so that $\mathrm{Cl}$ atoms terminating $\mathrm{Si}$ bonds in $\mathrm{SiO}_{2}$ targets are less stable. It follows that less energy is required to remove $\mathrm{Si}$ atoms by atomic bombardment from $\mathrm{Si}$ targets than from $\mathrm{SiO}_{2}$ targets.

As in the case of $\mathrm{Cl}$ beam etching, $\mathrm{F}$ atoms also have more difficulty penetrating $\mathrm{SiO}_{2}$ targets than $\mathrm{Si}$ targets. Figures 5(a) and 5(b) represent typical $\mathrm{Si}$ and $\mathrm{SiO}_{2}$ surface structures during $100 \mathrm{eV} \mathrm{F}$ beam etching. It is seen that, at $100 \mathrm{eV}$ impact energy, the thickness (i.e., depth) of the fluorinated layer is much larger for $\mathrm{Si}$ than that for $\mathrm{SiO}_{2}$, which is also shown in Table III. Unlike $\mathrm{Cl}$ beam etching of oxide, the $\mathrm{Si}-\mathrm{F}$ binding energy is higher than the $\mathrm{Si}-\mathrm{O}$ energy, so that $\mathrm{F}$ atoms terminating $\mathrm{Si}$ bonds in oxide are somewhat more stable than $\mathrm{Cl}$ atoms in oxide. This stronger chemical effect of $\mathrm{F}$ may account for higher yields $Y$ observed for $\mathrm{F}$ beam etching of oxide, as well as our observation that etching products contain more halogen atoms per $\mathrm{Si}$ atom for $\mathrm{F}$ beam etching than $\mathrm{Cl}$ beam etching with the same incident energy. The stoichiometry of etching products is shown in Fig. 6.

To represent silicon-oxide selectivities, we use the ratios of sputtering yields, rather than the ratios of etch rates. The ratios of sputtering yields are calculated from sputtering yield data in Table II and listed in Table IV. Here $S$ denotes the ratio of $\mathrm{Si}$ sputtering yield of the Si target to that of the $\mathrm{SiO}_{2}$ target with yield values taken from $Y$ in Table II. Similarly, $S_{2}$ denotes the same ratio with yield values taken from $Y_{2}$ in Table II. Figure 7 plots yield ratio $S$ for the three different cases: $\mathrm{Cl}(\bigcirc), \mathrm{F}(\square)$, and $\operatorname{Ar}(\triangle)$ beam etching. The fitting curves are obtained from the ratios of fitting curves 
sputtering yields

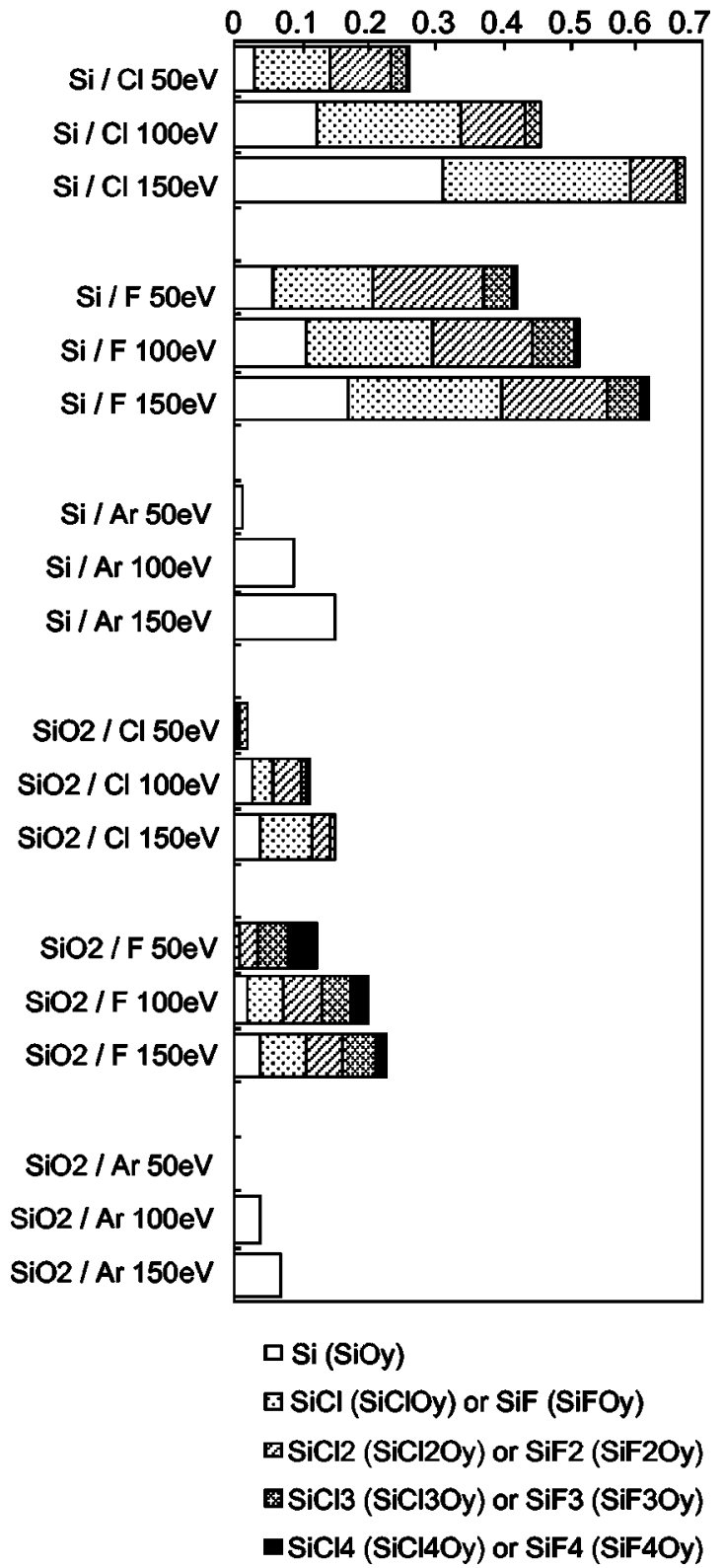

FIG. 6. Stoichiometry of etching products is shown. The horizontal axis represents the sputtering yield of each cluster (as denoted) that contains a single $\mathrm{Si}$ atom, i.e., the number of such clusters per incident atom.

TABLE IV. Silicon-oxide yield ratios $S$ calculated from simulation data $Y$ given in Table II are shown. Similarly $S_{2}$ are ratios calculated from $Y_{2}$ in Table II.

\begin{tabular}{ccc}
\hline \hline Beam & $S$ & $S_{2}$ \\
\hline Cl $50 \mathrm{eV}$ & 13 & 13 \\
Cl $100 \mathrm{eV}$ & 4.2 & 4.4 \\
Cl $150 \mathrm{eV}$ & 4.5 & 4.0 \\
F $50 \mathrm{eV}$ & 3.5 & 2.9 \\
F $100 \mathrm{eV}$ & 2.6 & 2.4 \\
F $150 \mathrm{eV}$ & 2.8 & 2.5 \\
Ar $50 \mathrm{eV}$ & 3.5 & 3.5 \\
Ar $100 \mathrm{eV}$ & 2.2 & 2.0 \\
Ar $150 \mathrm{eV}$ & 2.2 & 1.7 \\
\hline \hline
\end{tabular}

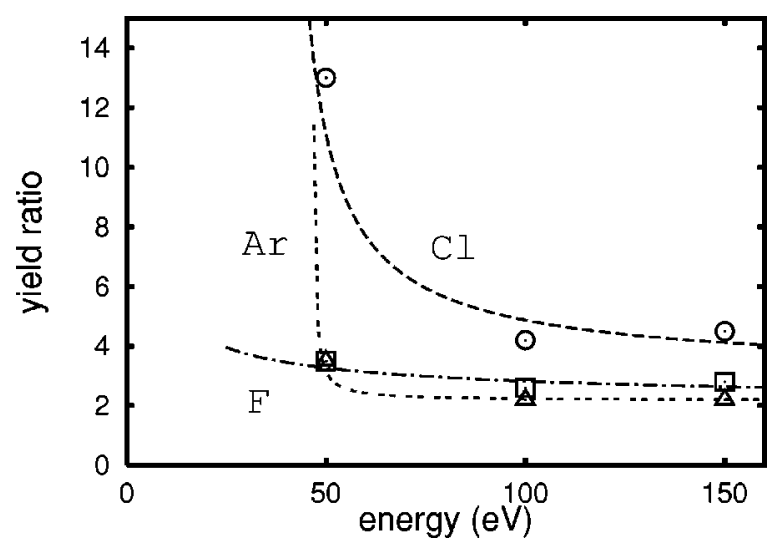

FIG. 7. $\mathrm{Si}$-oxide yield ratios ( $S$ in Table IV) for $\mathrm{Cl}(\bigcirc), \mathrm{F}(\square)$, and $\mathrm{Ar}(\triangle)$ beam etching are shown. The dashed, dotted-dashed, and dotted curves are fitting curves for yield ratios in $\mathrm{Cl}, \mathrm{F}$, and $\mathrm{Ar}$ beam etching processes, respectively, which are the ratios of the corresponding yield fitting curves given in Figs. 2 and 3.

shown in Figs. 2 and 3. The results presented here are similar to the observations in RIE experiments by Oostra et al. ${ }^{33}$

In summary, we have performed MD simulations for silicon and silicon dioxide etching by energetic halogens (F, or $\mathrm{Cl}$ ), using new sets of interatomic potentials representing $\mathrm{Si}-\mathrm{O}-\mathrm{F}$ and $\mathrm{Si}-\mathrm{O}-\mathrm{Cl}$ systems. Sputtering yields for silicon and oxide targets have been obtained from the MD simulations, which are in good agreement with experimental observations. Our MD simulations have also shown different target surface structures for fluorine and chlorine beam etching processes, which are essentially accounted for by the difference in atomic size and binding energy between fluorine and chlorine.

\section{ACKNOWLEDGMENT}

This work was supported in part by the 21 st Century Kawasaki Foundation.

\section{APPENDIX A}

In this appendix, we present the potential functions that we used in the MD simulations. Following Stillinger and Weber, ${ }^{1}$ we assume that the total potential energy of the system is given by

$$
\Phi \sum_{i<j} v_{2}(i, j)+\sum_{i<j<k} v_{3}(i, j, k) .
$$

Here, $v_{2}(i, j)$ is the pair-like interaction having the form

$$
\begin{aligned}
v_{2}(i, j)= & g(i, j) A_{i j}\left(B_{i j} r_{i j}^{-p_{i j}}-r_{i j}^{-q_{i j}}\right) \exp \left[\frac{C_{i j}}{r_{i j}-a_{i j}}\right] \\
& \text { if } r_{i j}<a_{i j},
\end{aligned}
$$

and $v_{2}(i, j)=0$, otherwise. By $r_{i j}=\left|\mathbf{r}_{j}-\mathbf{r}_{i}\right|$, we denote the distance between the $i$-th and $j$-th atoms located at $\mathbf{r}_{i}$ and $\mathbf{r}_{j}$. The parameters $A_{i j}, B_{i j}, C_{i j}, p_{i j}, q_{i j}$, and $a_{i j}$ depend only on the element types of $i$-th and $j$-th atoms. The "bond- 
TABLE V. Parameters of the interatomic potential functions for $\mathrm{Cl}-\mathrm{O}$ and F-O systems are shown.

\begin{tabular}{|c|c|c|c|c|c|}
\hline \multirow{3}{*}{$\begin{array}{l}\mathrm{Si}-\mathrm{O}-\mathrm{Cl} \\
v_{\mathrm{ClO}} \\
{[\mathrm{Eq} .(\mathrm{A} 2)]}\end{array}$} & \multicolumn{5}{|c|}{$\mathrm{Si}-\mathrm{O}-\mathrm{F}$} \\
\hline & $A_{\mathrm{ClO}}$ & 71.0 & $v_{\mathrm{FO}}$ & $A_{\mathrm{FO}}$ & 142.5 \\
\hline & $B_{\mathrm{ClO}}$ & 0.471 & [Eq. (A2)] & $B_{\mathrm{FO}}$ & 0.2772 \\
\hline & $C_{\mathrm{ClO}}$ & 3.55 & & $C_{\mathrm{FO}}$ & 4.111 \\
\hline & $p_{\mathrm{ClO}}$ & 3.13 & & $p_{\mathrm{FO}}$ & 3.0 \\
\hline & $q_{\mathrm{ClO}}$ & 1.53 & & $q_{\mathrm{FO}}$ & 1.0 \\
\hline & $a_{\mathrm{ClO}}$ & 1.8 & & $a_{\mathrm{FO}}$ & 1.6 \\
\hline & $R_{\mathrm{ClO}}$ & 1.0 & & $R_{\mathrm{FO}}$ & 0.9 \\
\hline & $D_{\mathrm{ClO}}$ & 0.1 & & $D_{\mathrm{FO}}$ & 0.1 \\
\hline \multirow{5}{*}{$\begin{array}{l}h_{\mathrm{ClClO}} \\
\text { [Eq. (A4)] }\end{array}$} & $\lambda_{\mathrm{ClClO}}$ & 1170 & $h_{\mathrm{FFO}}$ & $\lambda_{\mathrm{FFO}}$ & $1.135 \times 10^{6}$ \\
\hline & $\gamma_{\mathrm{ClClO}}^{\mathrm{Cl}}$ & 3.97 & [Eq. (A4)] & $\gamma_{\mathrm{FFO}}^{\mathrm{F}}$ & 13.44 \\
\hline & $\gamma_{\mathrm{ClClO}}^{\mathrm{O}}$ & 3.24 & & $\gamma_{\mathrm{FFO}}^{\mathrm{O}}$ & 3.441 \\
\hline & $a_{\mathrm{ClClO}}^{\mathrm{Cl}}$ & 2.0862 & & $a_{\mathrm{FFO}}^{\mathrm{F}}$ & 2.0862 \\
\hline & $a_{\mathrm{ClClO}}^{0}$ & 1.8 & & $d_{\mathrm{FFO}}^{\mathrm{O}}$ & 1.6 \\
\hline \multirow{5}{*}{$\begin{array}{l}h_{\mathrm{ClOCl}} \\
\text { [Eq. (A5)] }\end{array}$} & $\lambda_{\mathrm{ClOCl}}$ & 78.3 & $h_{\mathrm{FOF}}$ & $\lambda_{\mathrm{FOF}}$ & 4720 \\
\hline & $\gamma_{\mathrm{ClOCl}}^{\mathrm{Cl}}$ & 1.83 & [Eq. (A5)] & $\gamma_{\mathrm{FOF}}^{\mathrm{F}}$ & 3.608 \\
\hline & $a_{\mathrm{ClOCl}}^{\mathrm{Cl}}$ & 1.8 & & $a_{\mathrm{FOF}}^{\mathrm{F}}$ & 1.6 \\
\hline & $\cos \theta_{\mathrm{ClOCl}}^{0}$ & -0.221 & & $\cos \theta_{\mathrm{FOF}}^{0}$ & -0.04824 \\
\hline & $\alpha_{\mathrm{ClOCl}}$ & 1.0 & & $\alpha_{\mathrm{FOF}}$ & 1.285 \\
\hline \multirow{3}{*}{$\begin{array}{l}h_{\mathrm{OClO}} \\
{[\mathrm{Eq} .(\mathrm{A} 4)]}\end{array}$} & $\lambda_{\mathrm{OClO}}$ & $1.66 \times 10^{5}$ & $h_{\mathrm{OFO}}$ & $\lambda_{\mathrm{OFO}}$ & $3.092 \times 10^{4}$ \\
\hline & $\gamma_{\mathrm{OClO}}^{\mathrm{O}}$ & 5.78 & [Eq. (A4)] & $\gamma_{\mathrm{OEO}}^{\mathrm{O}}$ & 4.280 \\
\hline & $\alpha_{\mathrm{OClO}}^{\mathrm{O}}$ & 1.8 & & $\alpha_{\mathrm{OFO}}^{\mathrm{O}}$ & 1.6 \\
\hline \multicolumn{2}{|l|}{$h_{\mathrm{ClOO}^{\mathrm{a}}}$} & & $h_{\mathrm{FOO}}^{\mathrm{b}}$ & & \\
\hline
\end{tabular}

${ }^{\mathrm{a}} h_{\mathrm{ClOO}}=0$.

${ }^{\mathrm{b}} h_{\mathrm{FOO}}=0$.

softening function" $g(i, j)$ is assumed to be the same as that introduced by Watanabe et $a .^{22}$ for all oxygen-nonoxygen pairs.

The three-body term $v_{3}(i, j, k)$ in Eq. (A1) may be written as

$$
\begin{aligned}
v_{3}(i, j, k)= & h_{j i k}\left(r_{i j}, r_{i k}, \theta_{j i k}\right)+h_{i j k}\left(r_{j i}, r_{j k}, \theta_{i j k}\right) \\
& +h_{i k j}\left(r_{k i}, r_{k j}, \theta_{i k j}\right),
\end{aligned}
$$

with $\theta_{j i k}$ being the angle spanned by vectors $\mathbf{r}_{i j} \equiv \mathbf{r}_{j}-\mathbf{r}_{i}$ and $\mathbf{r}_{i k} \equiv \mathbf{r}_{k}-\mathbf{r}_{i}$ at vertex $\mathbf{r}_{i}$. To construct interatomic potentials for $\mathrm{Si}-\mathrm{O}-\mathrm{F}$ (or $\mathrm{Cl}$ ) systems, we employ the functional form ${ }^{1}$ for $h_{j i k}$ given by either

$$
h_{j i k}(r, s, \theta)=\lambda_{j i k} \exp \left[\frac{\gamma_{j i k}^{j}}{r-a_{j i k}^{j}}+\frac{\gamma_{j i k}^{k}}{s-a_{j i k}^{i}}\right],
$$

or

$$
\begin{aligned}
h_{j i k}(r, s, \theta)= & \lambda_{j i k} \exp \left[\frac{\gamma_{j i k}^{j}}{r-a_{j i k}^{j}}+\frac{\gamma_{j i k}^{k}}{s-a_{j i k}^{k}}\right] \\
& \times\left|\cos \theta-\cos \theta_{j i k}^{0}\right|^{2 \alpha_{j i k},}
\end{aligned}
$$

depending on species of the $i$ th atom if $r<a_{i i k}^{j}$ and $s$ $<a_{j i k}^{k}$. Otherwise, $h_{j i k}=0$. Here, $\lambda_{j i k}, \gamma_{j i k}^{j}, \gamma_{j i k}^{k}, \alpha_{j i k}^{j}$, $\alpha_{j i k}^{k}, \theta_{j i k}^{0}$, and $\alpha_{j i k}$ are parameters that depends on the species of $(i, j$, and $k)$ triplet. We have modified the original SW function by introducing a new parameter $\alpha_{j i k}$ in order to improve the parameter fitting.

The parameters in the Eqs. (A1)-(A5) for $\mathrm{Si}-\mathrm{F}, \mathrm{Si}-\mathrm{Cl}$, and $\mathrm{Si}-\mathrm{O}$ systems are found in Refs. $1-5$, and 22 . We have determined the remaining parameters by fitting these equations to potential data obtained from $a b$ initio calculations.
TABLE VI. Parameters of the three-body interatomic potential functions for $\mathrm{Si}-\mathrm{O}-\mathrm{Cl}$ (or F) systems are shown.

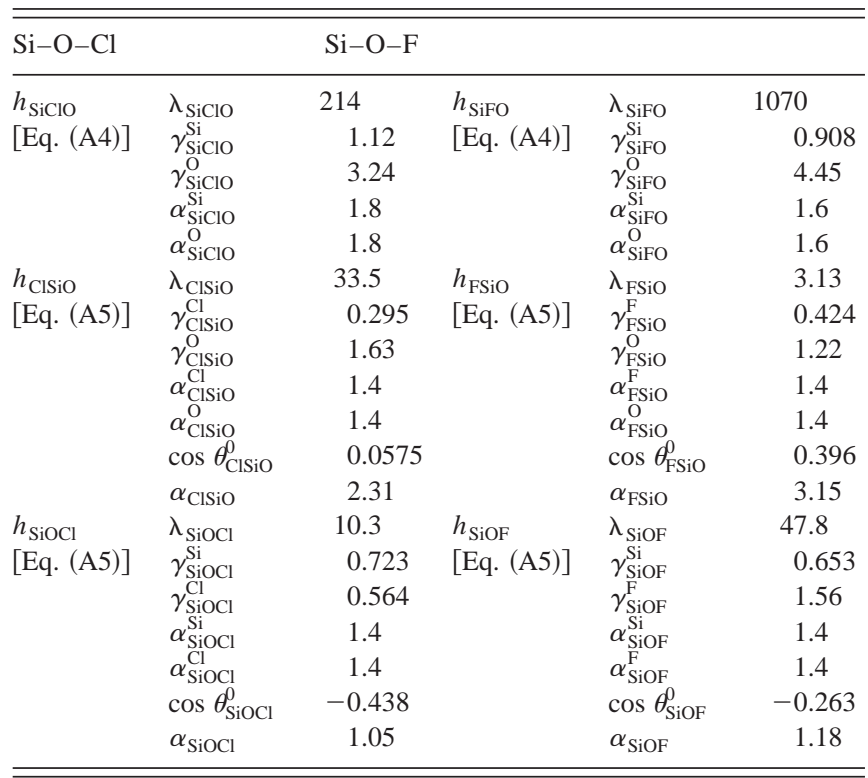

The obtained parameters are listed in Tables V and VI. The employed energy and length units are $50.0 \mathrm{kcal} / \mathrm{mol}(2.17$ $\mathrm{eV}$ ) and $2.0951 \AA$. Details of the derivation of these parameters will be published elsewhere. ${ }^{23}$

${ }^{1}$ F. H. Stillinger and T. A. Weber, Phys. Rev. B 31, 5262 (1985).

${ }^{2}$ F. H. Stillinger and T. A. Weber, J. Chem. Phys. 88, 5123 (1988).

${ }^{3}$ F. H. Stillinger and T. A. Weber, Phys. Rev. Lett. 62, 2144 (1989).

${ }^{4}$ T. A. Weber and F. H. Stillinger, J. Chem. Phys. 92, 6239 (1990).

${ }^{5}$ H. Feil, J. Dieleman, and B. J. Garrison, J. Appl. Phys. 74, 1303 (1993).

${ }^{6}$ M. E. Barone and D. B. Graves, J. Appl. Phys. 77, 1263 (1995).

${ }^{7}$ M. E. Barone and D. B. Graves, J. Appl. Phys. 78, 6604 (1995).

${ }^{8}$ B. A. Helmer and D. B. Graves, J. Vac. Sci. Technol. A 15, 2252 (1997).

${ }^{9}$ D. E. Hanson, A. F. Voter, and J. D. Kress, J. Appl. Phys. 82, 3552 (1997).

${ }^{10}$ N. A. Kubota, D. J. Economou, and S. J. Plimpton, J. Appl. Phys. 83, 4055 (1998)

${ }^{11}$ B. A. Helmer and D. B. Graves, J. Vac. Sci. Technol. A 16, 3502 (1998).

${ }^{12}$ B. A. Helmer and D. B. Graves, J. Vac. Sci. Technol. A 17, 2759 (1999).

${ }^{13}$ P. C. Weakliem, C. J. Wu, and E. A. Carter, Phys. Rev. Lett. 69, 200 (1992).

${ }^{14}$ P. C. Weakliem and E. A. Carter, J. Chem. Phys. 98, 737 (1993).

${ }^{15}$ L. E. Carter, S. Khodabandeh, P. C. Weakliem, and E. A. Carter, J. Chem. Phys. 100, 2277 (1994).

${ }^{16}$ D. E. Hanson, A. F. Voter, and J. D. Kress, J. Chem. Phys. 110, 5983 (1999).

${ }^{17}$ D. E. Hanson, A. F. Voter, and J. D. Kress, J. Vac. Sci. Technol. A 17, 1510 (1999).

${ }^{18}$ C. F. Abrams and D. B. Graves, J. Vac. Sci. Technol. A 16, 3006 (1998).

${ }^{19}$ A. Kubota and D. J. Economou, IEEE Trans. Plasma Sci. 27, 106 (1999).

${ }^{20}$ A. Kubota and D. J. Economou, IEEE Trans. Plasma Sci. 27, 1416 (1999).

${ }^{21}$ H. Ohta and S. Hamaguchi, Phys. Rev. Lett. 84, 6026 (2000).

${ }^{22}$ T. Watanabe, H. Fujiwara, H. Noguchi, T. Hosino, and I. Ohdomari, Jpn. J. Appl. Phys., Part 2 38, 366 (1999).

${ }^{23}$ H. Ohta and S. Hamaguchi, J. Chem. Phys. (submitted).

${ }^{24}$ I. Torrens, Interatomic Potentials (Academic, New York, 1972).

${ }^{25}$ R. Smith and D. E. Harrison Jr., Comput. Phys. 3, 68 (1989).

${ }^{26}$ H. J. C. Berendsen, J. P. M. Postma, W. F. van Gunsteren, A. DiNola, and J. R. Haak, J. Chem. Phys. 81, 3684 (1984).

${ }^{27}$ C. Steinbrüchel, Appl. Phys. Lett. 55, 1960 (1989).

${ }^{28}$ J. P. Chang and H. H. Sawin, J. Vac. Sci. Technol. A 15, 610 (1997).

${ }^{29}$ W. M. Holber and J. Forster, Proceedings of Symposium on Dry Process, 
Tokyo, 1989 (IEEJ, Technical Committee on Electron Devices, 1989), p. 9.

${ }^{30}$ J. P. Chang, J. C. Arnold, G. C. H. Zau, and H.-S. Shin, J. Vac. Sci. Technol. A 15, 1853 (1997).
${ }^{31}$ S. Tachi and S. Okudaira, J. Vac. Sci. Technol. B 4, 459 (1986).

${ }^{32}$ M. Seel and P. S. Bagus, Phys. Rev. B 28, 2023 (1983).

${ }^{33}$ D. J. Oostra, R. P. van Ingen, A. Haring, A. E. de Vries, and G. N. A. van Veen, Appl. Phys. Lett. 50, 1506 (1987) 